\title{
Writing Gesture Accompanied by Teachers in the Conversation Exchange Structure of Mathematical Learning
}

\author{
Mustafa A.H. Ruhama ${ }^{1,2}$, Cholis Sa'dijah", ${ }^{1, *}$ Abdur Rahman As'ari ${ }^{1}$, Sisworo ${ }^{1}$ \\ ${ }^{1}$ Department of Mathematics Education, Faculty of Mathematics and Natural Science, Universitas Negeri Malang, Indonesia \\ ${ }^{2}$ Department of Mathematics Education, Faculty of Teacher Training and Education, Universitas Khairun, Indonesia
}

Received March 2, 2020; Revised April 24, 2020; Accepted May 3, 2020

Copyright $(2020$ by authors, all rights reserved. Authors agree that this article remains permanently open access under the terms of the Creative Commons Attribution License 4.0 International License

\begin{abstract}
The aim of this study is to describe the writing gestures accompanied by directive and assertive speech of the teacher in the conversation exchange structure of mathematical learning. Data collection is done by recording and interviewing the teacher. The description of writing gesture along with the teacher's directive and assertive speech is obtained from the results of the recording during class learning and interviews. This case study investigates the writing gesture accompanied by teacher's speech in the conversation exchange structure of mathematical learning. The results of the study show that teachers use writing gestures along with explanations to focus attention and help students understand mathematical material in the information stage. At the initiation stage, the teacher asks questions to obtain students' responses. In the response phase, students respond verbally to the teacher's questions. This verbal response occurs because students have already understood the material asked by the teacher. At the feedback stage, the teacher justifies or confirms the student's verbal response or response by writing down the students' answers or verbal responses on the board. At the initiation stage, the teacher asks questions to students to obtain student responses. In the response phase, students respond verbally to the teacher's questions. This verbal response occurs because students have already understood the material asked by the teacher. At the feedback stage, the teacher uses writing gesture accompanied by the act of confirming or affirming and describing student answers on the board to focus students' attention and help students understand mathematical material.
\end{abstract}

Keywords Conversation Exchange Structure, Speech, Mathematics Learning, Writing Gesture

\section{Introduction}

Gesture and speech are often used in an integrated manner in communication [1]. Gesture serves as arm and hand movements only [1], body movements, especially the arms and hands [2], any body movements [3], [4] and gesture can be done using assistance with tools, especially stationery [5]. In this paper, gesture is the movement of fingers or stationery.

The use of teachers' gestures in mathematics learning has been a concern of researchers [6], [7], [8]. The teacher uses gesture to help students who have difficulty in learning mathematical concepts [8], when conveying/explaining mathematical ideas to students [6], [7], teachers' gestures will increase when delivering new concepts in mathematics learning [7]. The teacher's gesture classification in mathematics learning consists of pointing, representational and writing gesture [5]. Movement pointing at objects, locations, inscriptions, or people using stationery or fingers is called pointing gesture. Representational gesture is the movement of a hand or stationery that represents several objects, actions, concepts or relationships. Writing gesture is a movement to write ideas either that give rise to ex-members or not.

Speech is the smallest unit of verbal communication activity. Speeches can be used to express actions [9] and utterances that are known as speech acts. Speech acts into five types, namely: directive, commissive, assertive, expressive, and declarative [10]. Directive actions are utterances used by speakers to get others to do something, such as advice, requirements, requests, prohibitions, permissions, and asking questions. Commissive action is a speech that encourages speakers to do something, such as promising, swearing and vowing. Assertive action is also called representative action, namely speech that is planned and carried out by speakers of expressing something to the 
speech partner and the speech partner has the authority to accept or reject, for example stating, pointing, expressing, explaining, describing, affirming and describing. Expressive action is speech related to attitudes and feelings, for example expressing apologies, regrets, thanks and praise. Declarative action is a speech that functions to establish or justify an action or other utterance or previous speech, such as withdrawing, baptizing, punishing, firing, naming, ostracizing or disposing, and stipulating.

In the conversation exchange structure of mathematical learning, initiation and response are two utterances that are very important in classroom interactions [11]. The minimum requirements for conversations in mathematics learning are initiation and response. Information as an explanation is another element that characterizes conversations in class. Research from [12] showed that initiation, response, and feedback occur in teacher and student's conversations, this conversation exchange structure is called the Birmingham Model. Therefore, the exchange component in conversations in class consists of initiation, response, and feedback [13]. Initiation carried out by the teacher to get responses from students. Initiation carried out by students to get other students' responses. Initiation carried out by the teacher or student as a form of opening speech and acts as a stimulus. Initiation carried out by teacher or student who receives a response will be followed by feedback. In the structure of conversation exchange, response might be accompanied by feedback and maybe not. Based on the previous description, information, initiation, response, and feedback are the structure of conversation exchange. In learning mathematics, the teacher and students carry out the stages of the structure of conversation exchange, namely information, initiation, response, and feedback [11].

Teachers using gestures accompanied by utterances in mathematics learning have been investigated by [14], [5], [15]. Research from [14] showed that gesture with along by teacher's speech can simplify children's understanding, especially when new difficult concepts are introduced and complex language is used. Furthermore, gesture along with teacher's speech is very important in the regulation of learning because learning often presents new concepts that may be difficult for children and use complex language [14]. Pointing gesture along with teacher's speech can facilitate children's learning in symmetry material [14]. Pointing, representational and writing gesture with along by teacher's utterance can help or facilitate students' algebraic understanding. Teacher used pointing, representational and writing gesture with along utterance to students' respond questions and answers, introduce new material, and describe more abstract material [5]. Pointing gesture with along by teacher utterance in conversation help focus student attention and help students understand the material [15].

Research from [14], [5], [15] have not examined in depth about directive and assertive speech as [10], [11] found that teachers and students use directive and assertive speech in the structure of exchanges of mathematics learning conversation. Therefore, in this study, the researcher further described the directive and assertive speech of the teacher in the conversation exchange structure of mathematical learning which consisted of information, initiation, response and feedback.

\section{Methods}

This study uses a qualitative approach. This approach was chosen because (1) the researcher can be used to make interpretations of writing gestures accompanied the teacher's utterance in conversation exchange structure of mathematical learning, (2) the researcher can collect field data where the teacher can produce writing gestures and speech in conversation exchange structure of mathematical learning, and (3) The researcher can describe the writing gesture along with the teacher's speech in the conversation exchange structure of mathematical learning.

The type of research used is a case study. Researchers can study cases in one individual or several individuals from one location or several specific research locations. In this study, case study was directed at writing gestures accompanied teacher's utterance in conversation exchange structure of mathematical learning.

The subjects in this study were mathematics teachers of the $7^{\text {th }}$ grade Junior High School students of Ternate City, teachers of the $1^{\text {th }}$ grade Junior High School students of Ternate City and teachers of the $4^{\text {th }}$ grade Junior High School students of Ternate City. The process of selecting a subject is done until data saturation is obtained, meaning that the same or fixed characteristics appear from several subjects. The main instruments in the research are researchers and research supporting instruments are recording devices (camcorders, digital cameras and android mobile phones) and interview guidelines. Data collection is done by recording and interviewing the teacher. The description of writing gesture along with the teacher's directive and assertive speech is obtained from the results of the recording during class learning and interviews. The researcher identified writing gestures accompanied the teacher's directive and assertive speech in information, initiation, response and feedback from the conversations that occurred in the classroom. Some fragments of conversation in this study were selected as a representation of a conversation containing writing gestures accompanied by teacher's directive and assertive speech in information, initiation, response and feedback.

\section{Results and Discussion}

Teachers and students of IX.1 Class of State Junior High School 7 Ternate City together discuss the following questions: in what line of the pascal triangle is 64 ? The 
teacher writes $S_{n}=2^{n-1}$, since it is known that $S_{n}=64$ then the teacher writes $64=2^{n-1}$ and $2^{6}=2^{n-1}$ on the board. The teacher says "note the two sections, because the base number is the same, that is, two of them are in operation, that is, six equals $\mathrm{n}$ less than one or $n$ equals six plus one" and writes $6+1=n$ on the board using markers. Next, the teachers and students talk about which line of the pascal triangle is 64 ? While discussing this, the teacher presented a writing gesture with a speech. This is unambiguously revealed in the context of conversation A as follows.

Fragment of Conversation A

Teacher: $n$ equals six plus one and it is equals to?

Student: Seven (verbal response)

Teacher: Yes, seven (write 7 on the board using markers). Learn more write $7=n$ or $n=7$. So, the number 64 is in the seventh row (write 7 th on the blackboard using marker)

The pattern of conversation exchange structure of mathematical learning that occurs in conversation A (1) until (3) is Initiation-Response-Feedback. Beginning with the teacher asking the student as in A (1) for initiation, the student answers as in A (2) in response and the teacher justifies or confirms and interprets the student's feedback as in A (3). At the beginning of conversation A (1), the teacher uses directive speech, asking students questions. In the repetition of conversation A (3), the teacher used the writing movement 7 and $7=n$ or $n=7$ on the board using marker accompanied by the words "yes, seven". Spelling "yes, seven" is an affirmative speech, in which the teacher justifies or confirms the student's answer. Next, the teacher wrote the 7 th on the board with markers accompanied by the words "so the number 64 is the seventh". The phrase "so, number 64 is the seventh line" is an affirmative speech, which is to describe the student's verbal response. Based on the use of conversation A (3), the teacher uses a written gesture accompanied by an asertive speech, which is to justify or affirm the student's answer to the number 64 as the 7 th row in the conversation exchange structure especially feedback as shown in Figure 1.

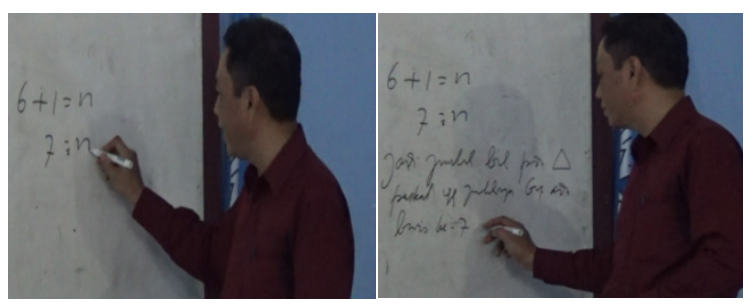

Figure 1. The Movment of Writing 7 and $7=n$ or $n=7$ and Writing 7 in Whiteboard Using Marker

The teacher uses a writing gesture accompanied by justifying or affirming and describing the students' answers to focus attention and help students understand that the number 64 is the 7 th row. This was revealed from the results of interview between the researcher $(\mathrm{R})$ with teacher
(T1) as follows.

R: Why did you write 7 and $7=n$ or $n=7$ and write 7 on the board using marker accompanied by speech?

T1: I wrote 7 and $n=7$ accompanied by speech like that to justify or confirm student answers. Then write 7 th on the board accompanied by speech to describe the students' answers or responses to focus attention and help students understand that the amount 64 is in the seventh row.

Teachers and students of IX.J Class of State Junior High School 1 Ternate City discuss the following questions: in which row of the pascal triangle having number of 256 ? The teacher writes $S_{n}=2^{n-1}$, because it is known $S_{n}=256$, the teacher writes $256=2^{n-1}$ and $2^{8}=2^{n-1}$ on the board. The teacher says "pay attention to the two segments, because the basic numbers are the same, namely two, the rank is operated, that is, eight equals $n$ minus one or $n$ equals eight plus one" and write $n=8+1$ on the board using a marker. Next, the teacher and student discuss about in which row of the pascal triangle which has the number of 256? When discussing this, the teacher brings up a writing gesture accompanied by speech. This is clearly described in the fragment of conversation B as follows.

Fragment of Conversation B

Teacher: $n$ equals to eight plus one equals to ?

Student: Nine (verbal response).

Teacher: Yes, nine (write 9 on the board using a marker).

Complete writing $\mathrm{n}=9$. So, the number is 256 is the

ninth line (write 9 th on the board using marker).

Teachers and students of IX.2 Class of State Junior High School 4 Ternate City discuss the following questions together: determine the number of pascal triangle numbers in the 5th row? The teacher writes $S_{n}=2^{n-1}$, because it is known that $n=5$, the teacher writes $S_{5}=2^{5-1}=2^{4}$ on the board. Next, the teacher and students discuss the number of pascal triangle numbers in the 5th row. When discussing this, the teacher brings up a writing gesture accompanied by speech. This was clearly described in the following section of conversation $\mathrm{C}$.

Fragment of Conversation $\mathrm{C}$

Teacher: Two squares equal to?

Student: Sixteen (verbal responses).

Teacher: Yes, sixteen (write 16 on the board using markers). Complete writing $S_{5}=16$. So, the number in the 5 th row is sixteen (write 16 on the board using marker). (3)

The pattern of conversation exchange structure that occurs in conversation fragments B (1) to (3) and C (1) to (3) is Initiation-Response-Feedback. Starting fromthat the teacher asks the students as in speech (1) as an initiation, students answer as in speech (2) as a response and the teacher justifies or confirms and describes students' answers as feedback as in speech (3). In a conversation fragment B (3) and C (3), the teacher uses writing gestures 
accompanied by assertive speech, which is to justify or confirm and describe students' answers about the the number 256 is the 6th line to- 9 and the number of numbers in line 5 is 16 in the structure of conversation exchange, especially feedback as shown in Figures 2 and 3 below.

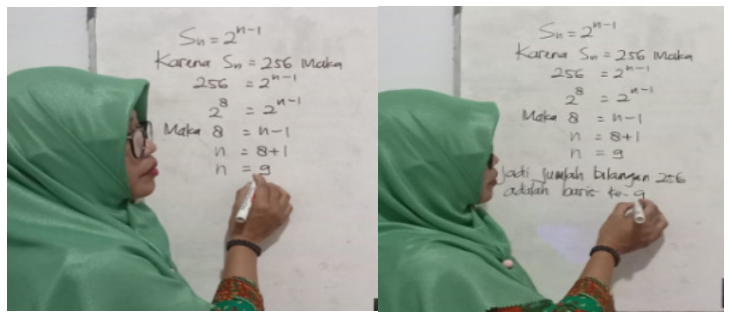

Figure 2. Writing Movement 9 and $n=9$ and Writing 9 on the board using a marker

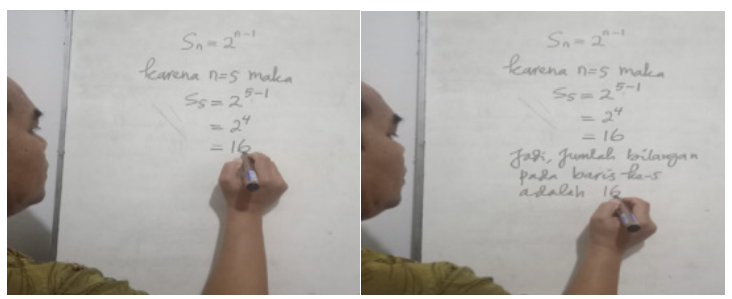

Figure 3. Writing Movement 16 and $S_{5}=16$ and Writing 16 on the board using a marker

In the feedback stage, the teacher (T2) uses writing gestures to justify or confirm and describe students' answers to focus attention and help students understand that the number 256 is the 9 th line. This was revealed from the results of the interview conducted by the researcher $(\mathrm{R})$ with the following teacher (T2).

R: Why do you write 9 and $n=9$ as well?

write the 9th on the board using a marker accompanied by speech?

T2: I wrote 9 accompanied by speech like that to justify or confirms student answers. Then write all 9 on the board accompanied by utterances to describe students' answers or responses to focus attention and help students understand the number of number 256 is the ninth row.

In the feedback stage, the teacher (T3) uses the writing gesture to justify or confirm and describe the students 'answers to focus attention and help students understand that the number of the 5 th row is 16 . This is revealed from the results of the interview conducted by the researcher (R) with the teacher (T3) follows.

R: Why did you do the 16 and $S_{5}=16$ movements as well write all 5 on the board using markers accompanied by speech?

T3: I wrote 16 accompanied by speech like that to justify or confirms student answers. Then write down the 5th on the board accompanied by utterances to describe students' answers or responses to focus attention and help students understand the number of numbers on the 5 th row is 16 .

The teachers (T1, T2, and T3) uses writing gestures accompanied by confirming or affirming and describing students' answers to focus attention and help students understand that the number 64 is the 7th row the Pascal triangle, the number 256 is the 9th line, and the number in line 5 is 16 in the structure of conversation exchange, especially feedback. The teacher uses writing gestures accompanied by justifying students 'answers to focus attention and help students' understanding [5].

This pattern ends with feedback where the teacher confirms or confirms and describes the student's response or response. Before the feedback occurs, the teacher begins with initiation where the teacher asks questions to students to get verbal responses or student answers. Verbal response is said because students have already know easily the answers based on their experiences and knowledge obtained in previous learning. If students have understood the mathematical concepts, students can verbally reiterate the concepts learned [16]. Initiations that get a response will be followed by feedback that functions as a cover [11]. Feedback is a speech in a conversation that is done to give comments or responses to previous speeches. In class interactions, responses or comments are used to respond to questions or statements [17]. The comments are in the form of justification, praise, affirmation, translation, rejection and improvement of answers. In feedback, the teacher provides reinforcement with justification and elaboration of the students' answers or responses [11]. Based on the fragment of conversation $\mathrm{A}$, the teacher uses writing gesture along with confirming or affirming and describing the student's answers that appear at the feedback stage that occurs in the pattern of Initiation-Response-Feedback to focus attention and help students understand the material.

Teachers and students of class IX.1 of the 7th Junior High School of the City of Ternate together discussed the question: it is known that the second term of the arithmetic sequence is 9 and the 10 th term is 41 . Determine the 100 th term of the sequence? The teacher writes $U_{2}=$ 9 and the arithmetic sequence formula, namely $U_{n}=a+$ $(n-1) b$ on the board. Write $U_{2}=a+(2-1) b=a+b$ and $a+b=9$ on the board. Next, the teacher and students together discuss about determining the equation if it is known that $n=10$ and $U_{n}=a+(n-1) b$. When discussing this, the teacher raises a writing gesture along with speech in conversation exchange structure. This was revealed in a fragment of conversation $\mathrm{D}$ as follows.

Fragment of Conversation D

Teacher: Note the arithmetic sequence formula, $n$ is equal to a plus the difference of $n$ minus one times $b$.

If, $n=10$ then $u$ ten equals to $a$ plus the difference of ten with one times $b$ (write $U_{10}=$ $a+(10-1) b$ on the whiteboard using marker) 
Teacher: Ten minus one?

Student: Nine (verbal response)

Teacher: Yes, nine. So, $u$ ten equals to $a$ plus nine times $b$ (he writes $U_{10}=a+9 b$ on the board using markers).

Next, the teacher interacts or discusses with students to look for the 100 th term of the sequence. The teacher together with students look for the values of $a$ and $b$ in the equation $a+b=9$ and $a+9 b=41$. The resultobtained is $a=5$ and $b=4$. Substituting $a=5$ and $b=4$ in the formula $U_{n}=a+(n-1) b$ so that it becomes $U_{n}=$ $4 n+1$. If $n=100$ then $U_{100}=4 \times 100+1=401$. So, the hundredth term is 401 .

Teachers and students of IX.J Class of State Junior High School 1 Ternate City together discuss the problem: An arithmetic sequence has the nth term formula, $U_{n}=3 n+2$, using the formula $U_{n}=3 n+2$ determine the 1 st term and the difference in the sequence the? The teacher writes the formula $U_{n}=3 n+2$ on the board. Next, the teacher and students together discuss about determining $U_{1}, U_{2}$, and $U_{3}$. When discussing this, the teacher brings up a writing gesture accompanied by utterances in the structure of learning conversation exchange. This is clearly revealed in the following section of conversation $\mathrm{E}$.

Fragment of Conversation $\mathrm{E}$

Teacher: Consider the formula for the nth term, $U_{n}=3 n+2$. If, $n=1$ then $\mathrm{u}$ one is equal to 3 times one plus two (write down $U_{n}=3 \times$ $1+2$ on the board using markers).

Teacher: Three times one plus two?

Student: Five (verbal response).

Teacher: Yes, five. So, u one equals 3 or the 1 st term equal to five (write $U_{1}=5$ or 1 st term $=5$ on the board using markers).

Next, the teacher interacts or discusses with students to find the $U_{2}$, and $U_{3}$ terms of the sequence. The results are obtained $U_{2}=8$, and $U_{3}=11$, so $U_{2}-U_{1}=8-5=3$ and $U_{3}-U_{2}=11-8=3$. So, the difference in row or $\mathrm{b}$ is 3 .

Teachers and students of IX.2 Class of State Junior High School 4 Ternate City together discuss the problem: note that the fourth term of the arithmetic sequence is 13 and the 20th term is 77 . Determine the 200th term of the sequence? The teacher writes $U_{4}=13$ and the arithmetic sequence formula, which is $U_{n}=a+(n-1) b$ on the board. Write $U_{4}=a+(4-1) b=a+3 b \quad$ and $a+3 b=13$ on the board. Next, the teacher and students together discuss about determining the equation if known $n=20$ and $U_{n}=a+(n-1) b$. When discussing this, the teacher brings up a writing gesture accompanied by utterances in the structure of learning conversation exchange. This was clearly revealed in the following section of $\mathrm{F}$ conversation.

Fragment of Conversation $\mathrm{F}$

Teacher: Consider the formula for arithmetic sequences, un equals to $a$ plus a difference $n$ less than one time $b$. If, $n=20$ then $u$ twenty equals to $a$ plus twenty with one multiplied by $b$ (write $U_{20}=a+$ $(20-1) b$ in whiteboard using markers).

Teacher: Twenty minus one?

Student: Nineteen (verbal response).

Teacher: Yes, nineteen. So, $u$ twenty is equal to $a$ plus nineteen times $b$ (write $U_{20}=a+19 b$ on the board using marker).

Next, the teacher interacts or discusses students to look for the 200th term of the sequence. The teacher together with students look for values $a$ and $b$ in the equation $a+3 b=13$ and $a+19 b=77$. The results obtained $a=1$ and $b=4$. Substitute $=1$ and $b=4$ in the formula $U_{n}=a+(n-1) b$ so that it becomes $U_{n}=4 n-3$ U. If $n=200$ then $U_{200}=4 \times 200-3=797$. Therefore, the hundredth term is 797 .

The pattern of conversation exchange structure of mathematical learning that occur in fragments of conversation D (1) to (4), E (1) to (4) and F (1) to (4) is Information-Initiation-Response-Feedback This pattern begins with the information stage in the form of material explanation from the teacher. Teachers provide explanations to students about subject matter during interaction in class [17]. After the information stage, the teacher initiates through questions, responses or students' answers as a reaction from the teacher's questions and the conversation ends with feedback from the teacher with justification or confirmation and elaboration of students' responses or answers. Conversational patterns in class can begin with information in the form of explanations, after the explanation is followed by questions as triggers or initiations, the next speech in the form of a response or response as a trigger in the previous speech is called a response and the conversation ends with feedback as justification or explanation and explanation [11]. In the response phase, students respond verbally to the teacher's questions. This verbal response occurs when students understand the material asked by the teacher. Verbal response is said because students have already known easily the answers to experiences and knowledge obtained in previous learning. If students have understood the mathematical concepts, students can verbally reiterate the concepts learned [16].

In the fragment of conversation D (1), the teacher wrote $U_{10}=a+(10-1) b$ on the board with a marker accompanied by speech "Note the arithmetic sequence formula, $n$ is equal to $a$ plus the difference of $n$ with one times $b$, if $n=10$ then $u$ ten equals $a$ ten plus the difference with one times $b$ ". Speech "if $n=10$ then $u$ ten equals to $a$ ten plus difference with one times" is an assertive speech, ie the teacher gives an explanation to students about $U_{10}=a+(10-1) b$. Fragment of conversation B (2), the teacher uses directive speech, which is asking questions to students. Fragment of 
conversation B (4), the teacher uses assertive speech, which is justifying or affirming student answers. Based on the fragment of conversation D (1), the teacher uses a writing movement accompanied by assertive speech, which is giving an explanation to students about $U_{10}=$ $a+(10-1) b$ in conversation exchange structure of mathematical learning especially information as shown in Figure 4 below:

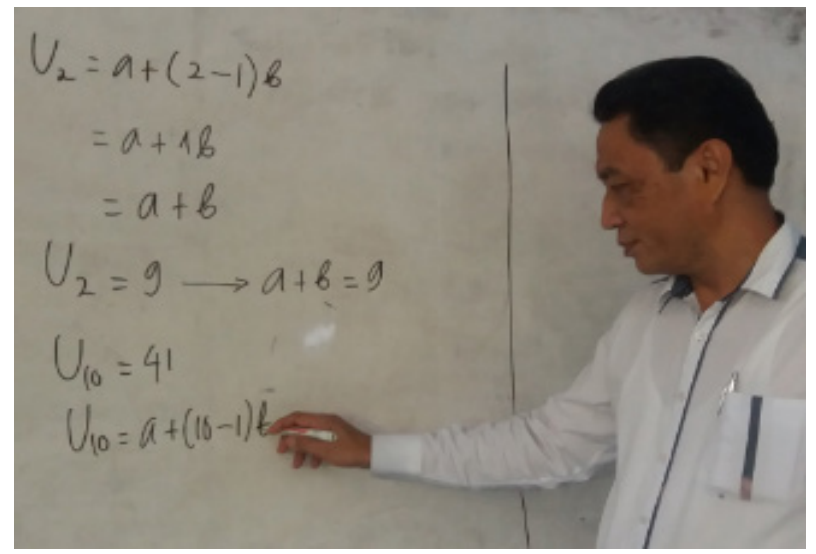

Figure 4. Writing Movement $U_{10}=a+(10-1) b$ on the Whiteboard using Marker

The teacher performs writing movement and it is accompanied by an explanation to focus attention and help students understand $U_{10}=a+(10-1) b=a+9 b$. This was revealed from the results of interview between the researcher (R) and the teacher (T1), which the detail can be seen as follows.

R: Please pay attention to the video recording (while asking some questions dealing with learning record). You wrote $U_{10}=a+(10-1) b$ on the whiteboard by using markers and says "Pay attention to the arithmetic, line formula $U_{10}=a+(10-1) b$, if $n=10$ then $u$ ten equals to $a$ plus the difference of ten with one times $b^{\prime \prime}$. Why did you write $U_{10}=a+$ $(10-1) b$ on the board using marker accompanied by speech like that?

T1: I wrote $U_{10}=a+(10-1) b$ on the board using a marker and i accompanied that with speech like that to give explanations to students about $U_{10}=a+$ $(10-1) b$ and wrote $a+9 b$ to focus attention and help students understand $U_{10}=a+(10-$ 1) $b=a+9 b$.

In fragment of conversation E (1) and F (1), the teacher uses writing gestures accompanied by assertive speech, which provides an explanation to students about $U_{1}=3 \times$ $1+2$, and $U_{20}=a+(20-1) b$ in the structure of exchanging mathematical learning conversions especially information as described in Figures 5 and 6 below.

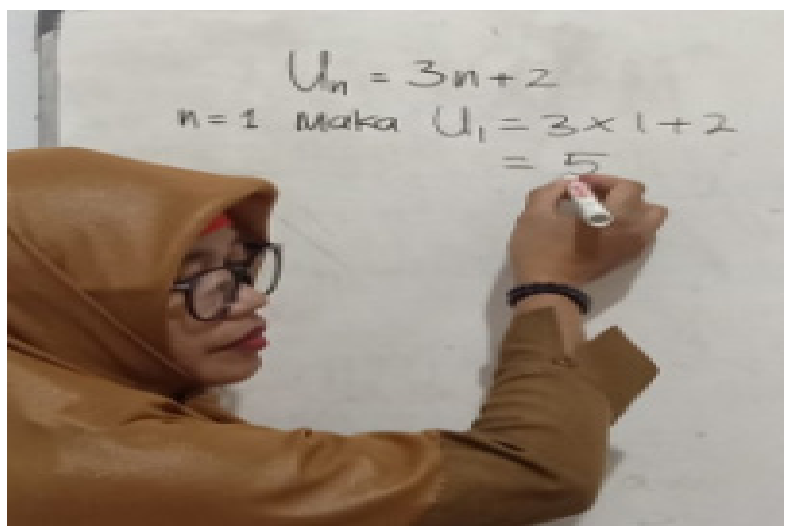

Figure 5. Writing Movement $U_{1}=3 \times 1+2$ on the blackboard using a Marker

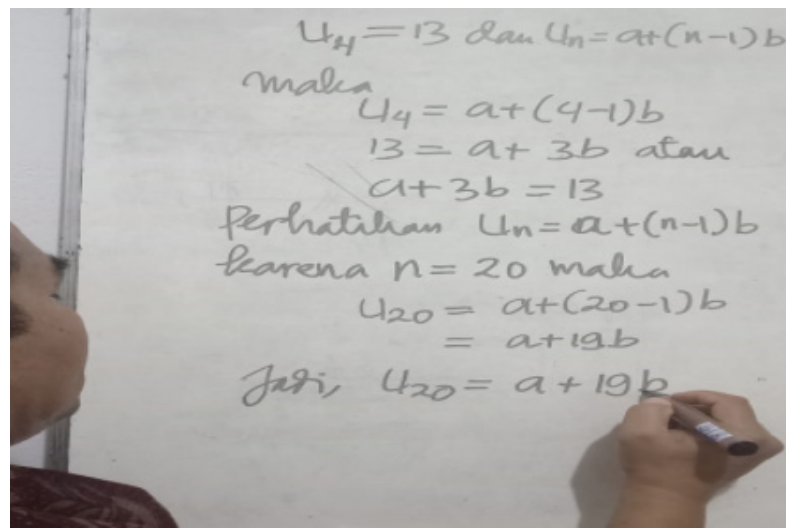

Figure 6. Writing Movement $U_{20}=a+(20-1) b$ on the blackboard using a marker

Teacher of IX.J Class of State Junior High School 1 Ternate City uses writing movements accompanied by giving explanations to focus attention and help students understand $U_{1}=3 \times 1+2=5$. This was revealed from the results of the resinterview by the researcher (R) with the teacher (T2) as follows.

R: Please pay attention to the video recording (while showing the recording learning). Mother writes $U_{1}=3 \times 1+2$ on the board using markers and say "Pay attention to the nth term formula, $U_{n}=3 n+2$. If, $n=1$ then $u$ one is equal to 3 times one plus two ". Why did you write it down? writes $U_{1}=3 \times$ $1+2$ on the board using markers accompanied by speech like that?

T2: I wrote $U$ writes $U_{1}=3 \times 1+2$ on the board with a marker accompanied by speech like that to give an explanation to students about writes $U_{1}=3 \times 1+2$ and write $U_{1}=5$ to focus attention and help students understand $U_{1}=3 \times 1+2=5$. 
Teacher of IX.2 Class of State Junior High School 4 Ternate City uses writing movements accompanied by giving explanations to focus attention and help students understand $U_{20}=a+(20-1) b=a+19 b$. This was revealed from the results of interview by the researcher $(\mathrm{R})$ with the teacher (T3) as follows.

$\mathrm{R}$ : Please pay attention to the video recording (while showing it learning recording results). You write $U_{20}=a+(20-1) b$ at the blackboard uses a marker and says "Pay attention to the formula sequence arithmetic, $U_{20}=a+(20-1) b$, if $n=20$ then $u$ twenty is equal to $a$ plus twenty by one $b$ ".

Why did you write it down? $U_{20}=a+(20-1) b$ on the board using markers accompanied by speech like that?

T3: I write $U_{20}=a+(20-1) b$ on the board using a marker speech like that to give an explanation to students about $U_{20}=a+(20-1) b$ and write $a+19 b$ to focus attention and help students understand

$$
U_{20}=a+(20-1) b=a+19 b .
$$

The teachers (T1, T2, and T3) uses writing movements or writing gesture accompanied by an explanation at the information stage to focus attention and help students understand $U_{10}=a+(10-1) b=a+9 b, U_{1}=3 \times 1+2=$ 5 and $U_{20}=a+(20-1) b=a+19 b$.Teacher used writing gesture along with an explanation during the conversation in class [15]. The teacher uses gesture when explaining mathematical material [6]. Teachers use writing gestures accompanied by teacher's speech to focus students 'attention and help students understand [5], writing gestures accompanied teacher's speech that are raised in conversations to focus students' attention [15]. Gesture accompanied by speech makes the explanation conveyed easier to understand [8]. The presence of gesture and speech can help students understand [6], [19], [20], [21]. The information stage, the teacher gave an explanation of the material to focus students' attention [11]. Based on fragments of conversation $\mathrm{B}$, the teacher uses writing gesture along with an explanation at the information stage that occurs in the Information, Initiation, Response Feedback pattern to focus attention and help students understand mathematical material.

\section{Conclusions}

Teachers use writing gestures along with explanations to focus attention and help students understand mathematical material in the information stage. At the initiation stage, the teacher asks questions to obtain students' responses. In the response phase, students respond verbally to the teacher's questions. This verbal response occurs because students have already understood the material asked by the teacher. At the feedback stage, the teacher justifies or confirms the student's verbal response or response by writing down the students' answers or verbal responses on the board. The teacher uses writing gesture along with an explanation at the information stage that occurs in the Information, Initiation, Response, Feedback pattern to focus attention and help students understand mathematical material.

At the initiation stage, the teacher asks questions to students to obtain students' responses. In the response phase, students respond verbally to the teacher's questions. This verbal response occurs because students have already understood the material asked by the teacher. At the feedback stage, the teacher uses writing gesture accompanied by the act of confirming or affirming and describing students' answers on the board to focus students' attention and help students understand mathematical material. The teacher uses writing gesture along with confirming or affirming and describing the students' answers to the feedback stage that occurs in the pattern of Initiation-Response-Feedback to focus attention and help students understand the material.

This study is still limited to writing gesture with assertive speech and directives on the conversation exchange structure of mathematical learning which include Information Initiation, Response, Feedback (Inf-I-R-F) and Response, Feedback, Initiation (I-R-F). There are opportunities to conduct research on other patterns that might arise during mathematics learning such as the pattern of Information, Initiation, Response (Inf-I-R), Initiation, Response, Initiation Advanced, Response (I-R-IA-R) and Initiation, Response/Initiation, Response (I-R/I-R) and on commissive, expressive, and declarative speech.

\section{Acknowledgments}

Our thanks go to Mr. Jainudin Jumat, teachers of State Junior High School 7 of Ternate City, Mrs. Nurya Yasin, teachers of State Junior High School 1 of Ternate City and Mr. Sofyan Sidik, teachers of State Junior High School 4 of Ternate City, Universitas Khairun, Universitas Negeri Malang, and the Republic of Indonesia Ministry of Research, Technology and Higher Education for their support in this research.

\section{REFERENCES}

[1] D. McNeill. Hand and Mind: What Gestures Reveal about Thought, University of Chicago Press, Chicago, 1992.

[2] A. Becvar, J. Hollan, E. Hutchin,. Representational Gesures as Cognitive Artifact for Developing Theories in a Scientific Laboratory, Resources, Co-Evolution and Artifacts: Theory in CSCW, 117-143, 2008.

[3] A. Sfard. What's All the Fuss about Gestures? A Commentary, Educational Studies in Mathematics, Vol.70, No.2, 191-200, 2009. 
[4] E. A. Cartmill, S. Beilock, S. Goldin-Meadow, S. A Word in The Hand: Action, Gesture and Mental Representation in Humans and Non-Human Primates, Philosophical Transaction of The Royal Society B, Vol.367, No.1585, 129-143, 2012.

[5] M.W. Alibali, M.J. Nathan. Teachers' Gestures as a Means Scaffolding Student's Understanding: Evidence from an Early Algebra Lesson, Video Research in The Learning Sciences, 349-365, 2007.

[6] M.W. Alibali, M.J. Nathan. Embodiment in Mathematics Teaching and Learning: Evidence From Learners' and Teachers' Gestures, Journal of the Learning Sciences, Vol. 21, No.2, 247-286, 2012.

[7] M.W. Alibali, M.J. Nathan, M.S. Wolfgram, R.B. Church, S.A. Jacobs, C.J. Martinez, E.J. Knuth. How Teachers Link Ideas in Mathematics Instruction Using Speech and Gestures: A Corpus Analysis, Cognition and Instruction, Vol.32, No.1, 65-100, 2014.

[8] S.D. Kelly, S.M. Manning, S. Rodak. Gesture Gives a Hand to Language and Learning: Perspectives from Cognitive Neuroscience, Developmental Psychology and Education, Language and Linguistics Compass, Vol.2, No. 4, 569-588, 2008.

[9] G. Leech. Principles of Pragmatics, Longman, London, 1983.

[10] J. R. Searle, D. Vanderveken. Foundation of Illocutionary Logic, Cambridge University Press, New York, 1985.

[11] M. A.H. Ruhama, Cholis Sa'dijah, A. R. As'ari, Sisworo. Pointing Gesture and Speech of Teachers in Mathematics Learning According to Information, Initiation, and Feedback, Journal of Physics, Vol.1028, No.1, 012151, 2018.

[12] J. M. Sinclair, R.M. Coulthard. Toward on Analysis of Discourse, Oxford University Press, London, 1975.
[13] M. Stubb. Discourse Analysis, The University at Chicago Press, Chicago, 1983.

[14] L. Valenzeno, M. W. Alibali, R. Klatzky. Teachers' Gestures Facilitate Students' Learning: A Lesson in Symmetry, Contemporary Educational Psychology, Vol.28, No.2, 187-204, 2003.

[15] R Bjuland, M. L.. Cestari, H. E. Borgersen. A Teacher's Use of Gesture and Discourse as Communicative Strategies in the Presentation of A Mathematical Task, Proceedings of the Joint Meeting of PME 32 and PME-NA XXX, 185-192, 2008.

[16] J. Kilpatrick, J. Swafford, B. Findell. Adding it Up: Helping Children Learn Mathematics, National Academy Press, Washington, 2001.

[17] K. Kumpulainen, D. Wray. Classroom Interaction and Social Learning, Routledge Falmer is an Imprint of the Taylor \& Francis Group, New York, 2002.

[18] V. C. Castellon, N. Enyedy. Teacher's Speech and Gesture as a Communicative and Strategic Tool to Convey and Discuss Mathematical Concepts in a Bilingual Algebra Classroom, AERA, 1-45, 2006.

[19] M. Francaviglia, R. Servidio. Gesture as a Cognitive Support to Solve Mathematical Problems, Psychology, Vol.2, No.2, 91-97, 2011.

[20] A.L. Hubard, K. Mcnealy, A.A. Scott-Van Zeeland, D.E. Callan, S.Y. Bookheimer, M. Dapretto. Altered Integration of Speech and Gesture in Children with Autism Spectrum Disorders, J. Brain and Behavior, Vol.2, No.5, 606-619, 2012.

[21] N. A. Ibraheem, R. Z. Khan. Vission Based Gesture Recognition Using Neural Network Approaches: A Review, International Journal of Human Computer Interaction, Vol.3, No.1, 1-14, 2012 